\title{
IDENTIFIKASI TINGKAT KEPATUHAN PASIEN GERIATRI YANG MENDERITA HIPERTENSI DISERTAI PENYAKIT PENYERTA DI RSU PANCARAN KASIH MANADO PERIODE SEPTEMBER-OKTOBER 2018
}

\author{
Widia Natalia Runtuwene ${ }^{1)}$, Weny Indayani Wiyono ${ }^{1)}$, Adithya Yudistira ${ }^{1)}$ \\ ${ }^{1)}$ Program Studi Farmasi FMIPA UNSRAT Manado, 95115
}

\begin{abstract}
Hypertension is one of chronic disease with commonly treatment for lifetime. The adherence of geriatric patients in following treatment very important that doesn't happen can lead to death. This type of research is a descriptive study. The population of this study amounted to 465 patients. The number of samples taken was 40 patients. The sampling technique is consecutive sampling. The level of adherence was measured using the Modified MoriskyAdherence Scale-8 (MMAS-8)questionnaire. From the results of this study it can be concluded that geriatric patients who do treatment at the manado pancaran kasih hospital have a high level of adherence of 10\%, have a moderate level of adherence of 40\%, and have a low level of adherence of 50\%. The results of this study found a problem related to the adherence of geriatric patients aged 60-69 years who took medication at the manado pancaran kasih hospital, namely because of forgetfulness and lack of information obtained from health workers regarding the patients condition and the importance of drugs to drink continue.
\end{abstract}

Keywords : Hypertension, Geriatric, Adherence.

\begin{abstract}
ABSTRAK
Hipertensi merupakan salah satu penyakit kronis dengan pengobatan yang umumnya seumur hidup.Kepatuhan pasien geriatri dalam menjalani pengobatan sangat penting agar tidak terjadi komplikasi berbagai penyakit yang dapat berujung pada kematian. Jenis penelitian ini adalah penelitian deskriptif.Populasi dari penelitian ini berjumlah 465 pasien.Jumlah sampel yang di ambil sebanyak 40 pasien.Teknik pengambilan sampel secara consecutive sampling.Tingkat kepatuhan di ukur dengan menggunakan Kuesioner MMAS-8 (Modified MoriskyAdherence Scale). Hasil penelitian ini dapat disimpulkan pasien geriatri yang melakukan pengobatan di RSU Pancaran Kasih Manado memiliki tingkat kepatuhan tinggi sebanyak 10\%, memiliki tingkat kepatuhan sedang sebanyak 40\%, dan memiliki tingkat kepatuhan rendah sebanyak 50\%. Hasil penelitian ini mendapatkan masalah terkait kepatuhan pasien geriatri yang berusia 60-69 yang melakukan pengobatan di RSU Pancaran Kasih Manado yaitu karena lupa dan kurangya informasi yang didapatkan pasien dari tenaga kesehatan terkait kondisi pasien dan pentingnya pengobatan secara kontinu.
\end{abstract}

Kata Kunci : Hipertensi, Geriatri, Kepatuhan. 


\section{PENDAHULUAN}

Populasi lanjut usia merupakan cerminan dari tingginya rata-rata usia harapan hidup (UHH) yang merupakan salah satu indikator keberhasilan pencapaian pembangunan nasional di bidang kesehatan. Usia lanjut mengalami kemunduran fungsi organ tubuh yang menyebabkan kelompok usia lanjut rawan terhadap serangan berbagai penyakit. Berdasarkan Riset Kesehatan Dasar tahun 2013 penyakit terbanyak yang di alami lanjut usia secara umum yaitu hipertensi dengan prevalensi sebesar 57,6\% (Zaenurrohmah dan Rachmayanti, 2017).

Proses pengobatan penyakit kronis, termasuk penderita hipertensi umumnya berlangsung seumur hidup. Hal ini seringkali mengakibatkan pasien merasa bosan terkait lama penggunaan obat, frekuensi obat, didukung pengetahuan pasien yang kurang mengenai penyakit yang diderita, dan pentingnya pengobatan untuk dilakukan secara kontinu. Alasan tersebut menyebabkan pasien memiliki kecenderungan untuk tidak patuh terhadap pengobatan. Sejalan dengan itu kepatuhan pasien dalam menjalani pengobatan merupakan faktor yang sangat penting untuk tercapainya efek terapi yang dapat berujung pada kesembuhan pasien, dan sangat penting dikarenakan hipertensi dapat menyebabkan terjadinya komplikasi penyakit yang dapat mengakibatkan kematian.

Fakta yang terjadi di masyarakat masih ditemui pasien lansia yang kurang patuh terhadap pengobatan yang diberikan banyak faktor yang dapat mempengaruhi kepatuhan pasien geriatri tersebut. Identifikasi tingkat kepatuhan pasien dapat menunjukan faktor-faktor resiko yang dapat mempengaruhi tingkat kepatuhan pasien geriatri dalam menjalani pengobatan. Teridentifikasinya faktor resiko tersebut diharapkan dapat memperbaiki kepatuhan pasien melalui berbagai upaya yang akan dilakukan berhubungan dengan masalah-masalah yang ditemui. Berdasarkan latar belakang tersebut di atas maka peneliti tertarik untuk melakukan penelitian tentang identifikasi tingkat kepatuhan pasien geriatri yang menderita hipertensi disertai penyakit penyerta di RSU Pancaran Kasih Manado.

\section{METODOLOGI PENELITIAN}

Penelitian ini dilakukan di RSU. Pancaran Kasih Manado pada periode bulan September sampai Oktober 2018. Jenis penelitian ini merupakan penelitian deskriptif, untuk menjabarkan suatu keadaan atau fenomena (status kepatuhan pasien) yang terjadi pada suatu saat. Teknik pengambilan sampel secara consecutive sampling, sampel dipilih berdasarkan kriteria inklusi dan dikumpulkan dalam waktu tertentu sampai memenuhi jumlah yang ditetapkan, dengan pengumpulan data pasien secara prospective.

\section{HASIL DAN PEMBAHASAN}

Tabel 1. Distribusi Karakteristik Pasien Hipertensi disertai Penyakit Penyerta $(n=40)$

\begin{tabular}{lcc}
\hline \multirow{2}{*}{ Karakteristik } & \multicolumn{2}{c}{ Total } \\
\cline { 2 - 3 } & $\mathrm{N}$ & $(\%)$ \\
\hline Usia & 19 & 47.5 \\
$60-64$ & 21 & 52.5 \\
65-69 & & \\
\hline Jenis Kelamin & 30 & 75 \\
$\quad$ Perempuan & 10 & 25 \\
$\quad$ Laki-Laki & & \\
& & \\
\hline
\end{tabular}




\begin{tabular}{lcc}
\hline Tingkat Pendidikan & & \\
SD/Sederajat & 4 & 10 \\
SMP/Sederajat & 4 & 10 \\
SMA/Sederajat & 22 & 55 \\
Perguruan Tinggi & 10 & 25 \\
\hline Status Pekerjaan & & \\
IRT & 17 & 42.5 \\
Pendeta & 1 & 2.5 \\
Pensiunan & 13 & 32.5 \\
Wirausaha & 4 & 10 \\
Wiraswasta & 4 & 10 \\
PNS & 1 & 2.5 \\
\end{tabular}

Penelitian yang dilakukan oleh Lukitasari (2013) menunjukan bahwa penyakit hipertensi paling banyak ditemukan pada rentang usia 60-74 tahun sebanyak 34 pasien $(47.2 \%)$ dari total 72 pasien, pada penelitian ini rata-rata pasien geriatri dengan usia di atas 60 tahun sampai 69 tahun. Menurut Smeltzer dan Bare (2001) yang dikutip oleh Novian $(2013,2014)$ semakin bertambahnya usia tekanan darah juga meningkat ini disebabkan karena terjadinya perubahan anatomi (struktur pembuluh darah) dan fisiologis pada pembuluh darah perifer dimana terjadi penurunan elastisitas otot polos pembuluh darah, aterosklerosis, dan hilangnya elastisitas jaringan ikat yang pada akhirnya menurunkan kemampuan untuk berelaksasi pada pembuluh darah lansia sehingga dapat menyebabkan hipertensi perifer yang sering terjadi pada kelompok usia lanjut. Nuraini (2015) memaparkan peningkatan umur akan menyebabkan beberapa perubahan fisiologis, pada usia lanjut terjadi peningkatan resistensi perifer dan aktifitas simpatik. Berkurangnya sensitivitas reflex baroreseptor yang berperan sebagai homeostasis tekanan darah, peran ginjal juga menurun dimana aliran darah ginjal dan laju filtrasi glomerulus menurun.
Setelah umur 45 tahun, dinding arteri akan mengalami penebalan oleh karena adanya penumpukan zat kolagen pada lapisan otot yang membuat pembuluh darah akan berangsur-angsur menyempit dan menjadi kaku.

Perempuan paling banyak menderita hipertensi sebanyak 30 pasien (75\%). Demikian pula hasil penelitian yang dilakukan oleh Khayyat (2017) perempuan paling banyak menderita hipertensi sebanyak 146 pasien (71.6\%) dari total pasien 204. Berdasarkan data rekam medik pasien geriatri RSU Pancaran Kasih Manado bulan mei 2018 paling banyak tercatat melakukan kunjungan ke poli geriatri dengan kasus menjalani pengobatan hipertensi ialah perempuan dengan jumlah 320 pasien dibandingkan dengan laki-laki hanya 145 pasien. Menurut Singalingging (2011) yang dikutip oleh Novitaningtyas (2014) perempuan akan mengalami resiko peningkatan tekanan darah setelah menopause karena hormon estrogen yang terdapat pada wanita yang berfungsi melindungi pembuluh darah dari proses terbentuknya aterosklerosis sudah hilang atau berkurang kuantitasnya.

Penelitian ini didapatkan pasien paling banyak ialah pasien dengan tingkat pendidikan SMA sebanyak 22 pasien (55\%). Demikian juga hasil penelitian Sepalawandika dan Shirly Gunawan (2016) penderita hipertensi paling banyak ialah dengan tingkat pendidikan SMA sebanyak 18 pasien $(37,5 \%)$ dari total 48 pasien. Tingkat pendidikan mempengaruhi kemampuan dan pengetahuan seseorang dalam menerapkan perilaku hidup sehat terutama dalam mencegah penyakit hipertensi.Semakin tinggi pendidikan kemampuan untuk menerima informasi 
semakin baik, semakin baik pengetahuan yang diperoleh maka kesadaran untuk berobat ke pelayanan kesehatan juga semakin baik (Puspita, 2016).

Penelitian ini mendapatkan pasien dengan status pekerjaan IRT paling banyak menderita hipertensi dengan jumlah 17 pasien $(42.5 \%)$ hasil penelitian ini sesuai dengan penelitian yang dilakukan oleh Subekti (2014) yang menunjukan bahwa yang paling banyak menderita hipertensi ialah dengan status pekerjaan IRT sebanyak 16 pasien (32\%) dari total 50 pasien. Hal ini disebabkan karena pasien dengan status IRT sibuk dalam mengurus rumah tangga yang menyebabkan pasien IRT kurang untuk keluar rumah melakukan pengobatan sehingga penyakit hipertensi yang umumnya tidak menunjukan tanda dan gejala yang bermakna menjadi lebih memburuk (Mangendai et al., 2017).

Tabel 2. Distribusi jenis obat antihipertensi

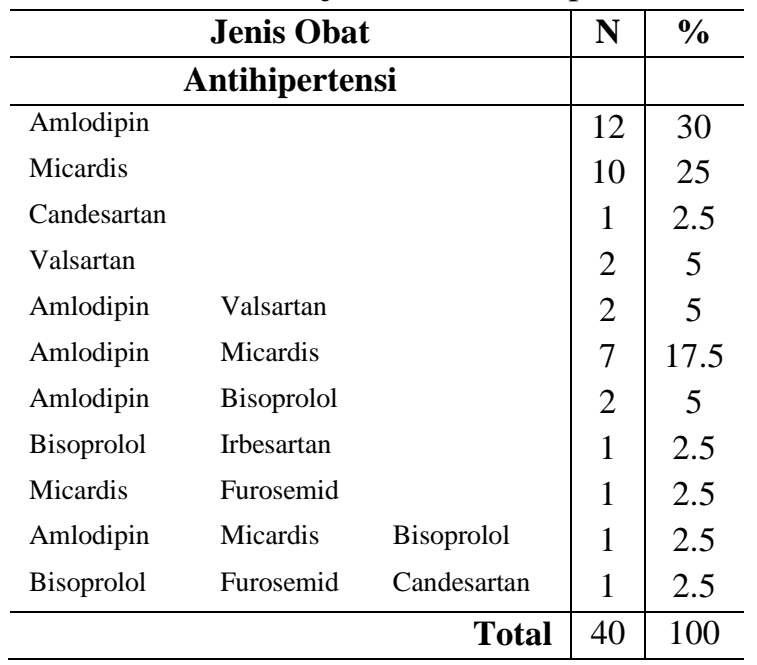

Tabel di atas menunjukan penggunaan obat antihipertensi yang paling banyak digunakan oleh pasien geriatri yang menjalani pengobatan ialah monoterapi, amlodipin sebanyak $30 \%$.

Tabel 3. Tingkat Kepatuhan Pasien Geriatri di RS Pancaran Kasih Manado

\begin{tabular}{ccc}
\hline $\begin{array}{c}\text { Tingkat Kepatuhan Pasien } \\
\text { Geriatri } \\
\text { (60-69 Tahun) }\end{array}$ & $\mathbf{N}$ & $\mathbf{( \% )}$ \\
\hline Tinggi & 4 & 10 \\
\hline Sedang & 16 & 40 \\
\hline Rendah & 20 & 50 \\
\hline TOTAL & 40 & 100 \\
\hline
\end{tabular}

Tingkat kepatuhan pasien geriatri yang menjalani pengobatan di RSU Pancaran Kasih Manado periode September-oktober paling banyak ialah dengan tingkat kepatuhan rendah, hasil tersebut didapatkan berdasarkan jawaban pasien melalui kuesioner pengukuran tingkat kepatuhan MMAS-8 (Morisky at al., 2008; Morisky and Di Matteo., 2011 in Verma et al., 2018).

Tabel 4. Distribusi pertanyaan kepatuhan (MMAS-8) berdasarkan jawaban pasien

\begin{tabular}{|c|c|c|c|c|c|}
\hline No & Item Kepatuhan & $\begin{array}{c}\mathrm{N} \\
(\mathrm{Ya})\end{array}$ & $\%$ & $\begin{array}{c}\mathrm{N} \\
\text { (Tidak) }\end{array}$ & $\%$ \\
\hline 1 & $\begin{array}{l}\text { Pernah lupa minum } \\
\text { obat }\end{array}$ & 30 & 75 & 10 & 25 \\
\hline 2 & $\begin{array}{l}\text { Dalam } 2 \text { minggu } \\
\text { terdapat hari tidak } \\
\text { minum obat }\end{array}$ & 13 & $\begin{array}{c}32 . \\
5\end{array}$ & 27 & 67.5 \\
\hline 3 & $\begin{array}{l}\text { Berhenti minum obat } \\
\text { karena efek samping } \\
\text { obat }\end{array}$ & 10 & 25 & 30 & 75 \\
\hline 4 & $\begin{array}{l}\text { Lupa membawa obat } \\
\text { ketika bepergian }\end{array}$ & 10 & 25 & 30 & 75 \\
\hline 5 & $\begin{array}{l}\text { Meminum obat } \\
\text { seluruhnya kemarin }\end{array}$ & 36 & 90 & 4 & 10 \\
\hline 6 & $\begin{array}{l}\text { Berhenti minum obat } \\
\text { ketika keadaan } \\
\text { membaik }\end{array}$ & 11 & $\begin{array}{c}27 . \\
5\end{array}$ & 29 & 72.5 \\
\hline 7 & $\begin{array}{l}\text { Memiliki masalah } \\
\text { dalam mematuhi } \\
\text { rencana pengobatan }\end{array}$ & 8 & 20 & 32 & 80 \\
\hline 8 & $\begin{array}{l}\text { Mengalami kesulitan } \\
\text { dalam mengingat } \\
\text { penggunaan obat }\end{array}$ & 21 & $\begin{array}{c}52 . \\
5\end{array}$ & 19 & 47.5 \\
\hline
\end{tabular}


Pasien geriatri yang menderita hipertensi disertai penyakit penyerta yang menjalani pengobatan di RSU Pancaran Kasih Manado yang meminum obat seluruhnya kemarin sebanyak $90 \%$ dengan masalah terkait kepatuhan paling banyak ialah pernah lupa minum obat sebanyak $75 \%$, mengalami kesulitan dalam mengingat penggunaan obat sebanyak $52.5 \%$, dalam 2 minggu terdapat hari tidak minum obat sebanyak $32.5 \%$ (lupa), berhenti minum obat ketika keadaan

Tabel 5. Distribusi frekuensi tingkat kepatuhan berdasarkan karakteristik dan Data klinis pasien $(\mathrm{N}=40)$

\begin{tabular}{|c|c|c|c|}
\hline \multirow[t]{2}{*}{ Karakteristik dan Data klinis } & \multicolumn{3}{|c|}{ Tingkat Kepatuhan } \\
\hline & Rendah & Sedang & Tinggi \\
\hline \multicolumn{4}{|l|}{ *Usia } \\
\hline 60-64 & $9 \quad(47.36 \%)$ & $7(36.84 \%)$ & $3(15.78 \%)$ \\
\hline $65-69$ & $11(52.38 \%)$ & $9(42.85 \%)$ & $1(4.76 \%)$ \\
\hline \multicolumn{4}{|l|}{ Jenis Kelamin } \\
\hline Perempuan & $13(43.33 \%)$ & $13(43.33 \%)$ & $4(13.33 \%)$ \\
\hline Laki-Laki & $7 \quad(70 \%)$ & $3(30 \%)$ & - \\
\hline \multicolumn{4}{|l|}{ Tingkat Pendidikan } \\
\hline $\mathrm{SD} /$ Sederajat & $3(75 \%)$ & 0 & $1(25 \%)$ \\
\hline SMP/Sederajat & $3(75 \%)$ & $1(25 \%)$ & 0 \\
\hline SMA/Sederajat & $12(54.55 \%)$ & $8(36.36 \%)$ & $2(9.91 \%)$ \\
\hline Perguruan Tinggi & $6(60 \%)$ & $4(40 \%)$ & 0 \\
\hline \multicolumn{4}{|l|}{ Status Pekerjaan } \\
\hline IRT & $7(41.59 \%)$ & $6(35.65 \%)$ & $4(23.76 \%)$ \\
\hline Pensiunan & $7(53.84 \%)$ & $6(46.15 \%)$ & - \\
\hline Wirausaha & $3(75 \%)$ & $1(25 \%)$ & - \\
\hline Wiraswasta & $3(75 \%)$ & $1(25 \%)$ & - \\
\hline PNS & $1(100 \%)$ & - & - \\
\hline Pendeta & $1(100 \%)$ & - & - \\
\hline \multicolumn{4}{|l|}{ Jumlah Obat } \\
\hline $1-2$ & $8(50 \%)$ & $7(43.74 \%)$ & $1(6.25 \%)$ \\
\hline $3-4$ & $10(47.62 \%)$ & $8(8.81 \%)$ & $3(14.29 \%)$ \\
\hline$\geq 5$ & $2(66.67 \%)$ & $1(33.33)$ & - \\
\hline \multicolumn{4}{|l|}{ Lama Menderita Hipertensi } \\
\hline 1-10 Tahun & $16(66.67 \%)$ & $14(58.33 \%)$ & $4(16.67 \%)$ \\
\hline 11-20 Tahun & $3(60 \%)$ & $2(40 \%)$ & - \\
\hline 30 Tahun & $1(100 \%)$ & - & - \\
\hline
\end{tabular}

Keterangan :

* : Kemenkes RI, 2017 membaik sebanyak 27.5\%, berhenti minum obat karena efek samping obat sebanyak $25 \%$, lupa membawa obat ketika bepergian sebanyak $25 \%$, dan memiliki masalah untuk mematuhi rencana pengobatan sebanyak $20 \%$. 
Usia termasuk salah satu faktor yang dapat mempengaruhi kepatuhan dimana usia 60-64 memiliki tingkat kepatuhan tinggi sebanyak $15.78 \%$ sedangkan usia 65-69 hanya memiliki tingkat kepatuhan tinggi sebanyak $4.76 \%$. Menurut Potter dan Perry yang di kutip oleh Fithria et al (2014) umur memberi pengaruh terhadap perilaku kesehatan yang dilakukan individu sehari-hari melalui pola pikir dan perilaku seiring dengan peningkatan usia dimana semakin tinggi usia maka semakin baik pemahaman terhadap konsep sehat dan perlunya menjaga kesehatan, sehingga upaya-upaya untuk mencegah timbulnya penyakit semakin baik hal tersebut menyebabkan terdapatnya pasien geriatri yang memiliki tingkat kepatuhan yang tinggi walaupun hanya sebesar (10.53\%) tetapi secara umum pasien geriatri pada usia ini lebih didominasi dengan tingkat kepatuhan yang rendah Semakin bertambahnya usia akan mengalami penurunan fungsi organ yang disebabkan karena berkurangnya jumlah sel dan asupan nutrisi yang mengakibatkan perubahan struktural dan fisiologis pada organ, salah satunya otak yang akan mengalami perubahan fungsi kognitif yang berupa kesulitan dalam mengingat kembali dan juga berkurangnya kemampuan dalam mengambil keputusan serta bertindak lebih lambat. Berdasarkan jawaban pasien melalui kuesioner pengukuran kepatuhan rata-rata pasien geriatri atau usia lanjut mempunyai masalah terkait kepatuhan paling banyak ialah karena faktor ketidaksengajaan yaitu karena lupa. Hasil penelitian ini sesuai dengan penelitian yang dilakukan oleh Fitrika et al, 2018 bahwa fungsi kognitif mempengaruhi kepatuhan yang dihubungkan dengan penurunan daya ingat pasien geriatri.
Perempuan memiliki tingkat kepatuhan tinggi sedangkan pasien lakilaki hanya memiliki tingkat kepatuhan yang sedang. Menurut Puspita (2016) terdapat perbedaan perilaku sakit antara laki-laki dengan perempuan dimana perempuan lebih memiliki keinginan untuk mengobatkan dirinya daripada laki-laki. Perbedaan antara laki-laki dan perempuan bukan hanya dari segi fisik saja namun dari cara berpikir dan bertindak serta bagaimana menyikapi suatu masalah, perempuan lebih memperhatikan kondisinya sehingga kepatuhan pasien perempuan dalam melakukan pengobatan lebih didominasi oleh perempuan (Pramestutie dan Silviana, 2016). Berdasarkan temuan dalam penelitian ini baik pasien laki-laki maupun perempuan rata-rata mengetahui penyakit hipertensi dapat menyebabkan komplikasi yang fatal, dapat mengakibatkan pecahnya pembuluh darah yang dapat mengakibatkan penyakit stroke yang mematikan.Tetapi berdasarkan kuesioner terlihat bahwa paling banyak yang tidak menghentikan pengobatan ketika merasa kondisi lebih baik dan ketika merasa kondisi lebih tidak baik ialah pasien perempuan sehingga melalui hal tersebut menunjukan pasien perempuan jauh lebih memperhatikan kondisinya sehingga membuat pasien perempuan menjadi lebih patuh dalam minum obat daripada laki-laki. Hasil penelitian ini sesuai dengan hasil penelitian Nurhidayati dan Parmono (2017) bahwa pasien perempuan lebih patuh dibandingkan dengan laki-laki.

Tingkat pendidikan bukan merupakan salah satu faktor yang dapat mempengaruhi kepatuhan pasien dalam menjalani pengobatan.Hal ini bisa disebabkan dari faktor pasien itu sendiri 
dimana setiap pasien memiliki motivasi berobat yang berbeda-beda, pengalaman pasien dengan keluarga atau kerabat yang menderita hipertensi yang menunjukan akibat yang buruk karena tidak minum obat, dan juga karena pasien geriatri sendiri mematuhi informasi yang disampaikan dokter atau petugas kesehatan yang menurut pasien dapat membuat keadaan atau kondisi penyakit mereka menjadi lebih baik. Berdasarkan kuesioner pasien dengan pendidikan SLTA paling banyak menjawab tetap meminum obat ketika merasa kondisi baik dan tetap meminum obat meskipun kondisi lebih buruk sebelum dikonsultasikan dengan dokter, dibandingkan dengan pasien dengan pendidikan S1 yang hanya sedikit yang tetap meminum obat dalam kondisi baik dan buruk, begitu juga dengan pendidikan SMP dan SD yang memiliki presentase yang sama dalam menjawab tetap meminum obat dalam kondisi baik dan buruk. Wahyudi et al (2017) melakukan penelitian tentang pengaruh demografi, psikososial, dan lama menderita hipertensi primer terhadap kepatuhan minum obat antihipertensi. Hasil penelitian tersebut menunjukan tidak adanya pengaruh antara pendidikan dengan kepatuhan.

Status pekerjaan merupakan faktor yang dapat mempengaruhi kepatuhan pasien. Pada penelitian ini didapatkan IRT memiliki tingkat kepatuhan tinggi, sedangkan Pensiunan, Wiraswasta dan Wirausaha, memiliki tingkat kepatuhan sedang, begitu juga dengan PNS dan Pendeta hanya dengan tingkat kepatuhan rendah. Semakin tingginya aktifitas seseorang dapat menurunkan kepatuhan pasien dalam penggunaan obatnya (WHO, 2003). Pasien yang berstatus IRT lebih memiliki tingkat aktifitas yang relative sedikit sehingga membuat terluangkannya waktu yang cukup untuk minum obat menurut waktu yang telah ditetapkan, berbeda dengan pasien yang berstatus pekerjaan wirausaha/swasta, pendeta, PNS dan pensiunan yang cenderung memiliki tingkat aktifitas yang lebih tinggi sehingga membuat kurang terluangkannya waktu untuk minum obat sesuai dengan jadwal yang telah ditetapkan dokter. Rasajati (2015) melalui penelitiannya tentang faktor-faktor yang berhubungan dengan kepatuhan pengobatan pada penderita hipertensi di wilayah kerja Puskesmas Kedungmundu kota semarang. Hasil penelitian tersebut menunjukan adanya hubungan antara status pekerjaan dengan kepatuhan pasien dalam menjalani pengobatan hipertensi.

Jumlah obat dapat mempengaruhi kepatuhan pasien, pengobatan 1-2 obat hanya memiliki tingkat kepatuhan tinggi yang sedikit dibandingkan dengan pengobatan 3-4 obat yang memiliki tingkat kepatuhan yang lebih besar sedangkan pengobatan dengan 5 obat hanya memiliki tingkat kepatuhan sedang. Penelitian ini pasien geriatri menjalani pengobatan paling banyak dengan monoterapi, selanjutnya ialah pasien dengan pengobatan lebih dari 1 jenis obat antihipertensi dan hanya 2 orang pada penelitian ini yang menjalani pengobatan dengan 3 antihipertensi sekaligus. Menurut JNC-7 penggunaan lebih dari 1 jenis obat mulai digunakan jika tekanan darah tergolong stage 2 (160/100) keadaan tekanan darah tidak terkontrol yang akan mempermudah terjadinya komplikasi oleh sebab itu pada penelitian ini pasien yang menjalani pengobatan lebih dari 1 jenis obat yaitu 3-4 obat lebih memiliki tingkat 
kepatuhan yang tinggi yang juga disertai penyakit lain sehingga hal tersebut menyebabkan pasien lebih memperhatikan kondisi penyakitnya. Sedangkan pasien yang menjalani pengobatan 5 obat kebanyakan pasien merasa bosan dengan jumlah obat yang banyakdan pasien mengkhawatirkan jumlah obat yang banyak tersebut dapat mempengaruhi ginjal sehingga membuat pasien yang menjalani pengobatan 5 obat pada penelitian ini hanya memiliki tingkat kepatuhan yang sedang. Hasil penelitian ini sejalan dengan penelitian Pratama dan Ariastuti (2014) bahwa penggunaan obat dengan terapi kombinasi memiliki tingkat kepatuhan yang jauh lebih tinggi daripada dengan penggunaan monoterapi.

Lama menderita merupakan salah satu faktor yang dapat mempengaruhi kepatuhan pasien geriatri. Lama menderita sama dengan lama penggunaan obat karena hipertensi merupakan penyakit yang tidak dapat disembuhkan tetapi dapat dikontrol, melalui penggunaan obat-obat antihipertensi (Suhadi, 2011). Wawancara dengan pasien geriatri banyak pasien sudah mengetahui pengobatan untuk penyakit hipertensi sudah seumur hidup. Hasil penelitian ini mendapatkan pasien geriatri merasa jenuh dalam menjalani pengobatan karena waktu dan penggunaan obat yang cukup lama sedangkan tingkat kesembuhan yang telah di capai seringkali tidak sesuai dengan yang diharapkan (Liberty et al., 2017). Hal ini terlihat dari jawaban pasien melalui kuesioner yang mendapatkan banyak pasien geriatri yang menghentikan pengobatan ketika merasa kondisi lebih baik yang juga didukung tidak terlalu cukupnya informasi yang didapatkan pasien terkait kondisi pasien dan pentingnya pengobatan dilakukan secara kontinu. Hasil penelitian ini sejalan dengan penelitian yang dilakukan Puspita (2016) yang mendapatkan bahwa pasien dengan lama menderita di bawah 5 tahun lebih patuh sebanyak $64.9 \%$ daripada yang menderita di atas 5 tahun yang disebabkan karena faktor jenuh dalam meminum obat. Dimana pada penelitian ini pasien dengan lama menderita 1-10 tahun paling banyak dengan lama menderita 1-5 tahun.

\section{KESIMPULAN}

Pasien geriatri yang menjalani pengobatan di RSU Pancaran Kasih Manado periode September-Oktober 2018 memiliki tingkat kepatuhan rendah sebanyak 50\%, memiliki tingkat kepatuhan sedang sebanyak 40\%, memiliki tingkat kepatuhan tinggi sebanyak $10 \%$.

Penelitian ini menemukan faktor resiko yang mempengaruhi tingkat kepatuhan pasien geriatri dalam menjalani pengobatan di RSU. Pancaran Kasih Manado periode September-Oktober 2018 ialah usia, jenis kelamin, status pekerjaan, jumlah obat dan lama menderita hipertensi. Dengan masalah terkait kepatuhan paling banyak berdasarkan jawaban pasien melalui kuesioner pengukuran tingkat kepatuhan MMAS-8 ialah karena ketidaksengajaan ketika tidak meminum obat yaitu lupa.Perempuan lebih patuh dibandingkan laki-laki karena perbedaan tingkat aktifitas dan laki-laki cenderung kurang dalam memperhatikan kondisi kesehatan.IRT lebih memiliki tingkat kepatuhan yang tinggi disebabkan karena lebih banyaknya waktu yang terluang dibandingkan dengan yang aktif bekerja di luar rumah.Kombinasi obat membuat pasien lebih patuh berkaitan dengan tingkat penyakit yang dialami pasien geriatri. Lama menderita hipertensi membuat pasien akhirnya merasa jenuh 
berkaitan dengan jumlah obat yang diterima, efek samping obat yang menimbulkan masalah kesehatan baru bagi pasien, serta peran dari tenaga kesehatan dokter, perawat dan tenaga farmasi yang membuat pasien geriatri tidak terlalu cukupnya informasi yang didapatkan pasien sehingga banyak pasien pada penelitian ini dengan masalah terkait kepatuhan paling banyak ke-2 ialah menghentikan pengobatan ketika merasa kondisi lebih baik dan menghentikan pengobatan ketika merasa kondisi tidak lebih baik sebelum dikonsultasikan ke dokter dan juga terdapatnya pasien yang merasa malu untuk menanyakan kondisi penyakit dan pengobatan yang dilakukan.

\section{DAFTAR PUSTAKA}

Fithria, and Isnaini, M. 2014. FaktorFaktor yang Berhubungan dengan Kepatuhan Berobat pada Penderita Hipertensi di Klinik Sumber Sehat Indrapuri Aceh Besar.Idea Nursing Journal.5(2): 61

Fitrika, Y., Saputra, K.Y., and Munarti, M. 2018. Hubungan Fungsi Kognitif Terhadap Kepatuhan Minum Obat Antihipertensi pada Pasien Lanjut Usia di Poliklinik Penyakit Dalam RS. Blud Meuroka Kota Banda Aceh. Jurnal Penelitian Kesehatan. 5(1): 16.

Kemenkes RI. 2017. Data dan Informasi. Profil Kesehatan Indonesia.

Liberty, I.A., Pariyana., and Roflin, E. 2017. Determinan Kepatuhan Berobat Pasien Hipertensi pada Fasilitas Kesehatan Tingkat 1.Jurnal Penelitian dan Pengembangan Pelayanan Kesehatan.1(1): 63-64.

Lukitasari.2013. Hubungan Tingkat Kepatuhan Kontrol pada Lansia dengan Hipertensi di Puskesmas Manisrenggo Klaten. Ilmu Keperawatan STIKES, Yogyakarta.

Novitaningtyas, T. 2014. Hubungan Karakteristik (Umur, Jenis Kelamin, Tingkat Pendidikan) dan Aktivitas Fisik dengan Tekanan Darah pada Lansia di Kelurahan Makam Haji Kecamatan Kartasura Kabupaten Sukoharjo. Fakultas Ilmu Kesehatan, Universitas Muhamadiyah. Surakarta.

Novian, A. 2014. Faktor yang Berhubungan dengan Kepatuhan Diit Pasien Hipertensi.Jurnal of Public Health. 3(3): 4

Nuraini, B. 2015. Risk Factor Of Hypertension.J Majority.5(4): 1012.

Nurhidayati, I., and Parmono.2017. Studi Komparasi Kepatuhan Penderita Hipertensi Dewasa dan Lansia pada Pengobatan Antihipertensi di Desa Cukil Wilayah Kerja Puskesmas Tangerang Kabupaten Semarang. The $5^{\mathrm{TH}} U R E C O L$ PROCEEDING. Yogyakarta, 18 February 2017. UAD Yogyakarta. Hlm 786-787. 
Pramestutie, H.R., and Silvana, N. 2016.Tingkat Pengetahuan Pasien Hipertensi tentang Penggunaan Obat di Puskesmas Kota Malang.Jurnal Farmasi Klinik Indonesia.5(1): 30-31.

Pratama, G.W., dan Ariastuti, N.L.P. 2014. Faktor-Faktor yang Mempengaruhi Kepatuhan Pengobatan Hipertensi pada Lansia Binaan Puskesmas Klungkung 1. Fakultas Kedokteran. Universitas Udaya

Puspita, E. 2016. Faktor-Faktor Yang Berhubungan Dengan Kepatuhan Penderita Hipertensi Dalam Menjalani Pengobatan [Skripsi].Fakultas Ilmu Keolahragaan, Semarang.

Rasajati, Q.P., Raharjo, B.B., and Ningrum, D.N.R. 2015. Faktor-Faktor yang Berhubungan dengan Kepatuhan Pengobatan pada Penderita Hipertensi di Wilayah Kerja Puskesmas Kedungmundu Kota Semarang. UNES Journal Of Public Health. 4(3) : 20-23.

Rosyida, L., Priyandani, Y., Sulistyarin, A., dan Nita, Y. 2015. Kepatuhan Pasien pada Penggunaan Obat Antidiabetes dengan Metode Pill-count dan MMAS-8 di Puskesmas Kedurus Surabaya. Jurnal Farmasi Komunitas. 2(2): 37.

Suhadi.2011. Analisis Faktor-Faktor yang Mempengaruhi Kepatuhan
Lansia dalam Perawatan Hipertensi di Wilayah Puskesmas Manisrenggo Klaten. Ilmu Keperawatan STIKES, Yogyakarta.

Subekti, R.Y. 2014. Analisis Faktor-Faktor yang mempengaruhi Tekanan Darah pada Usia Lanjut di Dusun Sumberan Sumberagung Moyudan Sleman Yogyakarta. Ilmu Keperawatan STIKES, Yogyakarta.

Verma, S., Rizvi, S.M., and Malik, S. 2018. Adherence to Medication in Patients with Pulmonary Arterial Hypertension.EC Pulmonology and Respiratory Medicine.7(3) : 143-145.

Wahyudi, C.T., Ratnawati, D., and Made, S.A. 2017. Pengaruh Demografi Psikososial dan Lama Menderita Hipertensi Primer terhadap Kepatuhan Minum Obat Antihipertensi. Jurnal JKFT. 2: 24-26.

Zaenurrohmah, D.H., dan R. Rachmayanti. 2017. Hubungan Pengetahuan dan Riwayat Hipertensi Dengan Tindakan Pengendalian Tekanan Darah Pada Lansia.Jurnal Berkala Epidemiologi. 5(2):175-176. 